\title{
Review on Electric Traction Systems Driving Induction Motor and Associated Power Quality Issues
}

\author{
Servesh Bharati \\ M. Tech Scholar \\ NRI Institute of Research \& Technology \\ Bhopal, M.P, India \\ serveshbharati@gmail.com
}

\begin{abstract}
The traction systems for electric vehicles have advanced considerably over recent years, with the application of different topologies of power converters for the control of various types of electric induction motors and permanent magnet. Furthermore, the evolution of power semiconductor elements of $\mathrm{Si}$ to $\mathrm{SiC}$ wideband have opened up lines of research and development in this area. The trend of manufacturer's traction systems is to reach compact systems where the power dissipation is high and the reduction of losses is minimal, for it the implementation of topologies of converters with $\mathrm{SiC}$ devices seems to be a good alternative of use to improve the performance of these systems. This paper studies the basic topologies of back to back converter in traction systems als well as the powr quality issues arriving in these systems.
\end{abstract}

Keywords: power converter dc / ac, electric vehicle, THD level

\section{INTRODUCTION}

The electric traction system is the most efficient of all other traction system such as steam and internal combustion (IC) engine type systems. It offers several benefits over other systems, including quick start and stop, very efficient, pollution-free, easy to handle and easy speed control. The way of giving the power supply to locomotive unit is generally referred as traction electrification system. Presently, there are four types of track electrification systems are available based on the availability of supply. These are

- DC traction system

- Single phase AC traction system

- Three phase AC traction system

\author{
Mrs. Madhu Upadhyay \\ Head of Department \\ NRI Institute of Research \& Technology \\ Bhopal, M.P, India \\ madyant44@gmail.com
}

- Composite traction system

With development, locomotive loads like steam and diesel engines became competent to each other resulting in electrification of railway systems. In the world of Indian railway system electric locomotive is amongst the important techniques used in railway system it gives results as comprehensive rise in speed. With the development and elaborating of power electronic equipment it reduces the size and weight of inverter and chopper drives due to which DC supply is still beneficial for use [9]

\section{A. Transformer and rectifier substation}

Generally in traction system, system used as supply to run electric trains includes only three phases or two phase electric power supply. There might be as imbalance in the system due to three phase supply but it is better than a single phase supply [9].

\section{B. Dc Link}

The DC link is used to maintain the voltage across the traction motor using variable capacitor. Now, output of rectifier is supplied to DC-Link then it is supplied to the locomotive motor [5].

\section{Locomotive design}

Several locomotives were used to run the wagons in traction system, these systems with power rating of $2.5 \mathrm{MW}$ is implemented for the DC series model in the system. A step down transformer is used in the system which is converts 
voltage from $25 \mathrm{KV}$ to $750 \mathrm{~V}$ supplying two-half controlled thyrister diode bridge rectifiers.

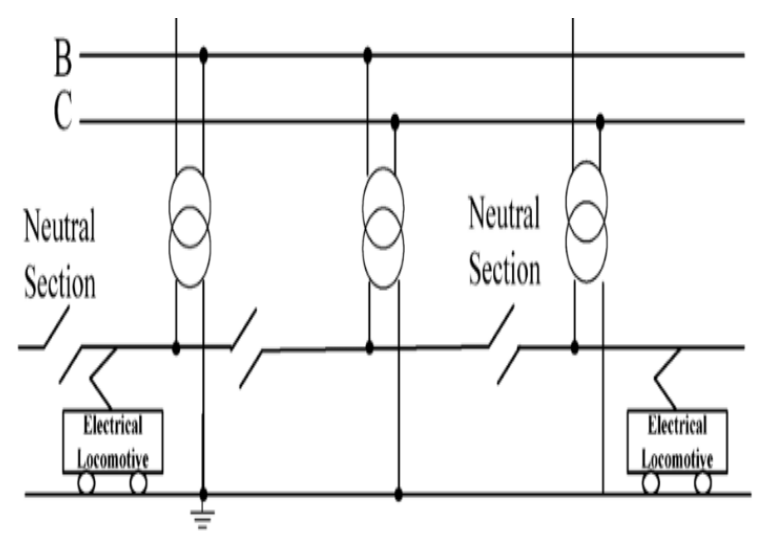

Fig. 1:- representation of traction supply to locomotive

\section{Power Quality Issues}

In electric railways single phase loads are used. Poor quality in the electric traction systems is the result of single phase load. Few power quality issues are listed below [4]:

- Negative sequence current in the three phase grid

- Consumption of high reactive power

- Harmonics

- Voltage unbalance

Power quality deformation can be defined as a set of disturbance/condition which is caused due to unwanted result for equipment .Power quality deformation is the issue which is caused mainly due to the increase in railway locomotive. Power quality deformations directly affect the three phase grid system. These issues are getting important due to the fast growing development in the field of high speed and heavy loading railway. Nowadays, PWM converters are mostly used in the railway locomotive due to which there is a decrease in the reactive power deformation and harmonics but due to the use of PWM converter voltage unbalance has become a prominent issue. So to increase the quality of the power proper traction transformers are designed For active, reactive power compensation active filters are used and to compensate the harmonics distortion, harmonic filters are used. In traction systems co-phase traction system were used so as to remove the disadvantage of two phase power supply system. Researchers are going on to reduce the power loss by using Hybrid Railway Power Conditioning Circuit (HRPC) using an LC branch [10].

\section{Co PHASE SYSTEMS}

To overcome the issue of two phase system, between two traction substation power is transferred by distribution line in same phase. Figure 2 shows the diagram of a co-phase traction system. Co-phase system increases the efficiency of the traction system and also reduces the cost. Another important power quality problem in the traction system is low system voltage. Low system voltage affects the efficiency of the locomotive and it also increases the power loss. Traction Transformer is only device that acts as the adapter between the three-phase source and the single-phase load in the system.

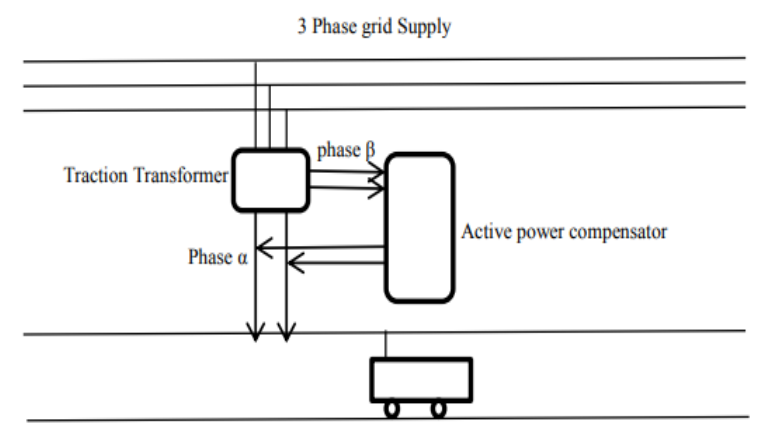

Fig. 2. Co-phase Traction Systems

Three phase supply is supplied from the external grid to the substation where special connected traction transformer converts it into single phase. From traction transformer phase $\alpha$ is connected to the load while phase $\beta$ provide power to the active power compensator for active compensation. Compensator is an ac-dc-ac converter. The compensation is done by multiplying load current with the value of voltage to get the fundamental power components [11].

\section{CONVERTERS IN ELECTRIC TRACTION SYSTEM}

For high-speed railway electrical drive systems, ac drive systems has been widely applied in the industry due to the advantages in performance, reliability, lighter quality and lower loss, as compared to dc systems [1]-[3]. Figure 3 shows a back to-back converter used in electrical railway traction systems, which is made up of a single-phase ac-dc converter on the grid side and three-phase dc-ac inverter on the motor-side. Usually such electric drive systems are susceptible to electrical faults under complex operating conditions such as static electricity, corrosion, humidity, and temperature. It was reported in [4] that around $38 \%$ of the faults in variable-speed ac drives are due to failures of power semiconductor devices. For high-speed 
railway electrical traction systems at high power and high voltage, the drive system has very strict reliability and safety requirements.

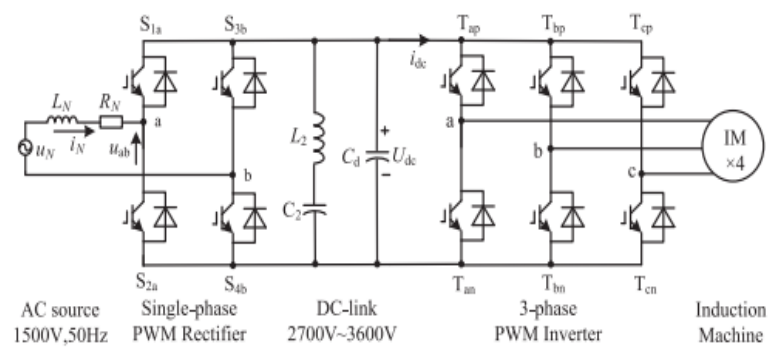

Figure 3 Back to back converter in three phase traction system

\section{USE OF FACTS DEVICES}

Flexible AC Transmission Systems (FACTS), uses power electronic devices are widely used for mitigation of harmonics and sag which will in turn improve quality of power and enhancing the traction system reliability. Railway is one of the major load on the grid. There it is necessary to control the harmonics and voltage fluctuation FACTS-devices provide a better control on reactive power, power factor and improve the reliability of existing installations. As the length of line increases line losses also increases and need for FACTS also gets important. The FACTS-devices can be switched or controlled shunt compensation, series compensation. These devices are fast current, voltage or impedance controllers.

\section{PRoblem IDENTIFICATION}

It was studied that as there is large load on traction system FACTS controller enhances the power transfer capability of existing line there by reduces the cost for new transmission line installation. SVC and STATCOM provide dynamic voltage support for high power traction system and prevents it from harmful voltage sag. The study on converter topologies has concluded that the controlling algorithms to these power electronic devices can help in overcoming the various power quality issues and voltage distortion reduction.

\section{VII.PROPOSED METHODOLOGY}

The study on various parameters associated with the electric traction system has been done. It is proposed to control the converter triggering algorithms to improve the THD and Voltage profile of the feeding to the loads. Also the FACTS devices along with power filter can be studied for further analyzing the quality of the output power. Efforts may be made to integrate the system control with the AI techniques

\section{CONCLUSION}

The efficient, safe, and intelligent running of rail transit trains cannot be separated from the comprehensive sensing of the entire system. The development of societies and economics entails the improvement of railways. The most important railway transportation routes are electrified which makes this system more competitive and environmentally more acceptable. In this paper, the monitoring of power quality parameters at the point of electric railway system connection to the transmission system was described. The effects of various power electronic devices on the quality issues were studied and also some of the solutions for them were described. The electric traction system is the need to the future eco friendly transportation so has a wide area of research for improvement in its efficiency.

\section{REFERENCES}

[1] Nicholas Jenkins, Goran Strbac, Olimpo AnayaLara," "Control of DFIG-Based Wind Generation for Power Network Support", VOL. 20, NO. 4, NOVEMBER 2005

[2] Ma. Ángeles Martín Prats, Jan T. Bialasiewicz, , Leopoldo Garcia Franquelo, José Ignacio León, Juan Manuel Carrasco, Eduardo Galván, Narciso MorenoAlfonso, Ramón C. Portillo Guisado, "Power-Electronic Systems for the Grid Integration of Renewable Energy Sources: A Survey", VOL. 53, NO. 4, AUGUST 2006.

[3] Marco Liserre, Frede Blaabjerg, Adrian V. Timbus, Remus Teodorescu, Frede Blaabjerg, "Overview of Control and Grid Synchronization for Distributed Power Generation Systems" VOL. 53, NO. 5, OCTOBER 2006.

[4] Adel Tabakhpour L, S. M. Mousavi G, Ewald F. Fuchs, Kamal Al-Haddad, "Power Quality Issues in Railway Electrification: A Comprehensive Perspective", IEEE Transactions on Industrial Electronics, DOI 10.1109/TIE.2014.2386794.

[5] Chandan Vaishnav, Vivek Shrivastava, Laxman Singh, "Performance Analysis of Hybrid Network of Indian Traction Power System using Renewable Energy Sources" 16 IEEE DOI 10.1109/ICMETE.2016.101

[6] G. Celli, S.B. Tennakoon, F. Pilo, "Voltage regulation on $25 \mathrm{kV}$ AC Railway systems by using Thyristor Switched Capacitor", Proceedings of 9th international conference on harmonics and quality of power, Vol.2, PP.633-638. 
[7] G.Bhuvaneswari, Bhim singh, Vipin Garg, "Improved Power Quality AC-DC Converter for Electric Multiple Units in Electric Traction", 0-7803-9525-5/06/\$20.00 (C)2006 IEEE.

[8] H.P.Kincha, K.G.Sheshadri, K.Parthasarathy, D.Thukaram, U.J.Shenoy, "A Real time DSP based quadrilateral relay for distance protection of $25 \mathrm{KV}$ AC traction overhead equipment," POWERCON 2004, International conference on Power System Technology 2004 -PP. 1339-1344.

[9] Electric railways traction tutorial,part 3 traction power supplies by R.J Hill.power engineering journal 1994.

[10] Fatima Fini, Prabhakarkarthikeyan S. Harmonic analysis on various traction transformers in cophase traction systems, Ain shams Engineering journal; Vol. 2015.p.627-638.

[11] Abhishek Kaudi, Ajit Kumar Barisal, Shubhra jyoti sahu "A Study of Various Traction Transformers \& Active Power Compensator in Co-Phase Traction Systems", 1st International Conference on Power Engineering, Computing and Control, PECCON-2017, 2-4 March 2017 